13,03

\title{
Электронно-стимулированная десорбция атомов лития из слоев лития на поверхности $\mathrm{Li}_{x} \mathrm{Au}_{y}$
}

\author{
() Ю.А. Кузнецов, М.Н. Лапушкин
}

Физико-технический институт им. А.Ф. Иофрфе,

Санкт-Петербург, Россия

E-mail: lapushkin@ms.ioffe.ru

Поступила в Редакцию 27 мая 2021 г.

В окончательной редакции 27 мая 2021 г.

Принята к публикации 2 июня 2021 г.

\begin{abstract}
Впервые созданы полупроводниковые 2D-слои $\mathrm{Li}_{x} \mathrm{Au}_{y}$ на поверхности золота, напыленного на вольфрамовую подложку. Исследованы процессы электронно-стимулированной десорбции атомов Li в системе $\mathrm{Li} / \mathrm{Li}_{x} \mathrm{Au}_{y} / \mathrm{Au} / \mathrm{W}$. Показано, что процессы электронно-стимулированной десорбции происходят в монослое $\mathrm{Li}$ и ближайшем к нему слое $\mathrm{Li}_{x} \mathrm{Au}_{y}$. Предложена модель электронно-стимулированной десорбции атомов $\mathrm{Li}$ в системе $\mathrm{Li} / \mathrm{Li}_{x} \mathrm{Au}_{y} / \mathrm{Au} / \mathrm{W}$.
\end{abstract}

Ключевые слова: электронно-стимулированная десорбция, литий, золото, полупроводник, интерметаллид.

DOI: 10.21883/FTT.2021.10.51460.127

\section{1. Введение}

Облучение электронами поверхности твердого тела может приводить к десорбции атомов и ионов, что открывает возможности для исследования поверхности. Электронно-стимулированная десорбция (ЭСД) атомов наблюдается только с поверхности полупроводников и изоляторов при энергии возбуждающих ЭСД электронов менее $200 \mathrm{eV}$. С поверхности металлов электронностимулированная десорбция атомов не наблюдается, так как происходит быстрая релаксация возбужденных состояний, которое не позволяет за это время десорбироваться атому. Поэтому с помощью метода ЭСД возможно производить исследования перехода металл-полупроводник (диэлектрик) для адсорбированных слоев и 2D-слоев нанесенных на поверхность. Ранее с помощью ЭСД исследована адсорбция атомов щелочных металлов на различных поверхностях интерметаллидов щелочных металлов (CsAu, $\mathrm{NaAu}, \mathrm{KAu})$ [1-4].

Интерметаллиды золото-щелочной металл известны еще с середины прошлого века [5]. Интерметаллиды щелочных металлов с золотом вызывают к себе интерес, так как в них золото выступает в роли аниона [6], а не катиона как в большинстве соединений золота. Еще более удивительным является то, что в ряде случаев интерметаллиды щелочных металлов с золотом могут образовывать полупроводниковые соединения. Процесс синтеза интерметаллидов может происходить не только при высоких температурах, но и при комнатной температуре при напылении атомов щелочных металлов на поверхность золота. Формирование интерметаллида при напылении атомов щелочных металлов на поверхность приводит к созданию 2D-пленок интерметаллида с толщиной от одного монослоя интерметаллида и более.
Интерметаллид CsAu является полупроводником, что было показано как для массивных образцов $[5,7,8]$, так и для 2D-пленок интерметаллида [2,9]. Расчеты методом функционала плотности (DFT) показывают, что интерметаллид CsAu является широкозонным полупроводником с шириной запрещенной зоны $2.6 \mathrm{eV}$ [10]. Расчеты методом функционала плотности электронной структуры для интерметаллидов $\mathrm{LiAu}, \mathrm{KAu}, \mathrm{NaAu}$ [11], $\mathrm{NaAu}_{2}$ [12], $\mathrm{LiAu}_{5}, \mathrm{NaAu}_{5}, \mathrm{KAu}_{5}$ [13] показывают, что эти интерметаллиды являются металлами. Однако ряд экспериментов, выполненных с помощью метода ЭСД, показывают, что 2D-пленки интерметаллидов $\mathrm{K}_{x} \mathrm{Au}_{y}[1]$ и $\mathrm{Na}_{x} \mathrm{Au}_{y}$ [2], полученным при $T=300 \mathrm{~K}$, являются полупроводниками. Причем стоит отметить, что полученный при $T \sim 1000 \mathrm{~K}$ интерметаллид $\mathrm{Na}_{x} \mathrm{Au}_{y}$ [14] является широкозонным полупроводником с шириной запрещенной зоны $2.7 \mathrm{eV}$. Также было показано, что и полученный при $T \sim 1000 \mathrm{~K}$ интерметаллид $\mathrm{K}_{x} \mathrm{Au}_{y}$ явлется полупроводником [4].

Процесс формирования интерметаллидов щелочных металлов с золотом при температурах близких к комнатным происходит в несколько стадий. При напылении на золото пленки щелочного металла менее одного монослоя не происходит диффузии атомов щелочных металлов в золото и, следовательно, не происходит формирование интерметаллида золото-щелочной металл. При напылении на поверхность золота дозы щелочного металла более одного монослоя приводит к диффузии атомов щелочного металла в золото с формированием интерметаллидов золото-щелочной металл различной стехиометрии. Следует отметить, что при таком способе создания интерметаллида на поверхности всегда будет присутствовать монослой щелочного металла.

В [15] показано, что пленка $\mathrm{Li}-\mathrm{Au}$, полученная при насыщении атомами $\mathrm{Li}$ пленки золота толщиной 
5 монослоев, имеет металлический характер. Этот факт подтверждается рассчитанным металлическим характером соединения $\mathrm{Li}_{x} \mathrm{Au}_{y}[11,13]$.

Исследованиям адсорбции атомов Li на золоте и их взаимодействию было уделено меньше всего внимания по сравнению с исследованиями адсорбции других щелочных металлов на золото. Так, например, в [16] было показано формирование сплава $\mathrm{Au}-\mathrm{Li}$ в золотом электроде в электрохимической ячейке, с электролитом, в составе которого содержится $\mathrm{LiPF}_{6}$. В последние годы началось исследование $\mathrm{Au}_{x} \mathrm{Li}_{y}$ нанобъектов, например, в [17] созданы наночастицы LiAu с размером $5 \mathrm{~nm} \mathrm{и}$ были исследованы колебательные свойства этих наночастиц. Фазовая диаграмма системы $\mathrm{Au}-\mathrm{Li}$ была опубликована в [18].

Целью настоящей работы было создать 2D-пленку интерметаллида $\mathrm{Li}_{x} \mathrm{Au}_{y}$, детально рассмотреть физические процессы, протекающие при облучении электронами системы $\mathrm{Li} / \mathrm{Li}_{x} \mathrm{Au}_{y}$, и на этой основе предложить модель ЭСД атомов Li в этой системе.

\section{2. Эксперимент}

\section{1. Материалы}

В качестве подложки исследуемых образцов использовались вольфрамовые ленты. Ленты предварительно прогревали при $1800 \mathrm{~K}$ в атмосфере кислорода при давлении $1 \cdot 10^{-6}$ Torr в течение $3 \mathrm{~h}$. Золото напыляли на ленту при $300 \mathrm{~K}$ из прямонакальной вольфрамовой трубки, в которую были помещены куски золотой фольги с чистотой 99.99\%. Литий напыляли на ленту при $T=300 \mathrm{~K}$ из прямонакального испарителя путем термического восстановления окиси лития алюминием. Концентрация атомов лития на поверхности ленты определялась по времени напыления постоянным потоком, интенсивность которого измерялась по току поверхностной ионизации на Ir ленте, и составляла в монослое атомов лития $1.0 \cdot 10^{15}$ atom $/ \mathrm{cm}^{2}$. Концентрация напыленного Au определялась по времени напыления при постоянном потоке $\mathrm{Au}$, который калибровался с помощью термодесорбционной спектроскопии, и составляла в монослое атомов золота $1 \cdot 10^{15}$ atom $/ \mathrm{cm}^{2}$. Эксперименты были выполнены при $300 \mathrm{~K}$.

\section{2. Приготовление образцов}

Использовались два способа приготовления образцов. В первом случае, на чистую вольфрамовую ленту при комнатной температуре напыляли фиксированное количество золота, после чего напыляли необходимое для измерений ЭСД варьируемое количество атомов лития. После проведения измерений поверхность вольфрама очищалась и приготавливалась заново. Во втором случае, на чистую вольфрамовую ленту при комнатной температуре напыляли необходимое для измерений ЭСД варьируемое количество золота, после чего напыляли

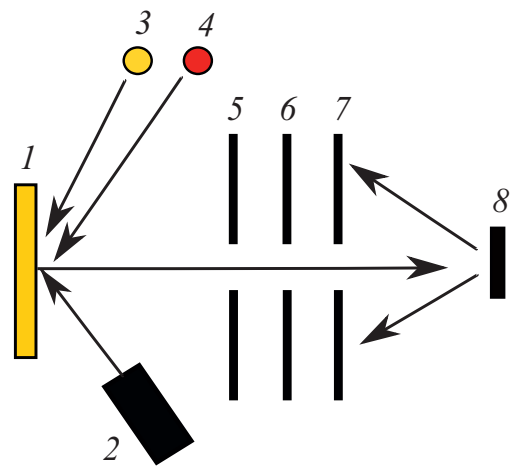

Рис. 1. Схема эксперимента. 1 - образец, 2 - источник электронов, 3 и $4-\mathrm{Au}$ и $\mathrm{Li}$ испарители, 5, 6 - электроды, задерживающие ионы, десорбирующихся при электронном облучении образца, 7 - коллектор ионов, 8 - поверхностная ионизационная лента.

фиксированное количество атомов лития. После проведения измерений поверхность вольфрама также очищалась и готовилась заново.

\section{3. ЭСД}

Предлагаемые в данной работе исследования проведены сверхвысоковакуумной установке „Спектрометр ЭСД“, схема эксперимента приведена на рис. 1. Давление остаточных газов в установке не превышало $5 \cdot 10^{-10}$ Torr. Эксперименты проводили при $T=300 \mathrm{~K}$.

Вольфрамовую ленту с нанесенным на нее слоем $\mathrm{Li}_{x} \mathrm{Au}_{y}$ облучали пучком электронов с энергией в диапазоне 0-200 eV. Десорбирующиеся при этом атомы Li ионизировались на нагретой до $T=2000 \mathrm{~K}$ иридиевой ленте. Вероятность поверхностной ионизации атомов Li на иридии при такой температуре равна единице [19].

ЭСД атомов характеризуется величиной выхода ЭСД $q$, равной отношению плотности десорбирующегося потока атомов к плотности потока возбуждающих ЭСД электронов. Установка „Спектрометр ЭСД“ позволяла регистрировать выход ЭСД атомов цезия $q$, измерять зависимость этого выхода $q$ от энергии возбуждающих электронов, количества нанесенного на подложку $\mathrm{Li}$ и золота.

\section{3. Результаты и обсуждение}

ЭСД атомов Li с поверхности одного монослоя $\mathrm{Au}$ напыленного на W(100) не наблюдается ни при каких покрытиях Li, т. е. не происходит реакции атомов лития с атомами золота в монослойной пленке $\mathrm{Au}$ на W(100). Это согласуется с ранее полученными результатами по исследованию адсорбции атомов $\mathrm{Na}, \mathrm{K}$ и $\mathrm{Cs}$ на монослойной пленке золота, когда ЭСД атомов щелочных металлов не наблюдается [4-6] и исследованиями адсорбции атомов натрия и цезия на пленках золота, напыленных на вольфрам [20]. Если же нанесено покрытие 


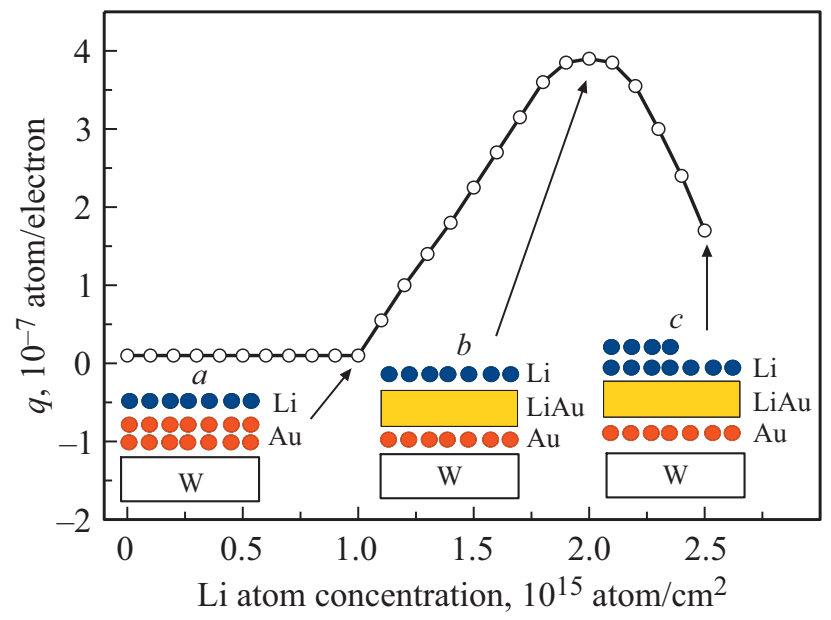

Рис. 2. Выход q атомов Li при ЭСД с вольфрама, покрытого двумя монослоями золота, при $T=300 \mathrm{~K}$ в зависимости от концентрации адсорбированного лития $n_{\mathrm{Li}}$ для энергии бомбардирующих электронов $64 \mathrm{eV}$. Схемы при напылении $\mathrm{Li}$ и $\mathrm{Au}$ на W: $a$ - для 2 монослоев $\mathrm{Au}$ и 1 монослоя $\mathrm{Li}$; $b$ - для 2 монослоев $\mathrm{Au}$ и 2 монослоев $\mathrm{Li} \mathrm{c}$ образованием 2D-слоя $\mathrm{LiAu} ; c$ - для 2 монослоев $\mathrm{Au}$ и 2.5 монослоев $\mathrm{Li} \mathrm{c}$ образованием 2D-слоя LiAu.

$\mathrm{Au}$ больше, чем 1 монослой, то при напылении атомов лития, возможно, регистрировать ЭСД атомов лития.

На рис. 2 показана зависимость выхода ЭСД $q\left(n_{\mathrm{Li}}\right)$ атомов $\mathrm{Li}$ с поверхности $\mathrm{W}$, покрытого двумя монослоями $\mathrm{Au}$, при $T=300 \mathrm{~K}$ от поверхностной концентрации $\mathrm{Li}$, адсорбированного на поверхности $\mathrm{Au} / \mathrm{W}$. При дозе напыления атомов лития менее, чем $1.0 \cdot 10^{15}$ atom $/ \mathrm{cm}^{-2}$ (1 монослой $)$, ЭСД атомов $\mathrm{Li}$ не наблюдается и не формируется соединение $\mathrm{Li}_{x} \mathrm{Au}_{y}$ (схема $a$ на рис. 2). При дозе напыления атомов лития больше, чем $1.0 \cdot 10^{15}$ atom $/ \mathrm{cm}^{-2}$ (1 монослой) начинает наблюдаться ЭСД атомов Li. Это означает, что в промежутке между верхним монослоем атомов лития и ближайшим к поверхности вольфрама монослоем золота начинает формироваться полупроводниковая пленка $\mathrm{Li}_{x} \mathrm{Au}_{y}$. Увеличение дозы напыленных атомов $\mathrm{Li}$ приводит к линейному росту $q$ вплоть до дозы напыленного $n_{\mathrm{Li}}=1.8 \cdot 10^{15} \mathrm{atom} / \mathrm{cm}^{2}$. Дальнейшее напыление атомов лития приводит к замедлению роста выхода ЭСД атомов $\mathrm{Li}$, а при $n_{\mathrm{Li}}=2.0 \cdot 10^{15} \mathrm{atom} / \mathrm{cm}^{2}$ (2 монослоя) наблюдается максимум выхода ЭСД атомов Li. Такое поведение можно объяснить тем, что происходит дальнейшее формирование $2 \mathrm{D}$-слоя $\mathrm{Li}_{x} \mathrm{Au}_{y}$ между верхним монослоем атомов лития и ближайшим к поверхности вольфрама монослоем золота. Продолжение напыления атомов $\mathrm{Li}$ приводит к уменьшению выхода ЭСД атомов Li. Мы предполагаем, что при напылении дозы $n_{\mathrm{Li}}>1.0 \cdot 10^{15}$ atom $/ \mathrm{cm}^{2}$ происходит формирование полупроводникового соединения $\mathrm{Li}_{x} \mathrm{Au}_{y}$ с дефицитом атомов лития в соединении, а при напылении дозы $n_{\mathrm{Li}}=2.0 \cdot 10^{15} \mathrm{atom} / \mathrm{cm}^{2}$ происходит формирование по- лупроводникового соединения LiAu (схема $b$ на рис. 2). При дозе напыления $n_{\mathrm{Li}}>2.0 \cdot 10^{15} \mathrm{atom} / \mathrm{cm}^{2}$ не происходит дальнейшего изменения стехиометрии образовавшегося соединения LiAu. Спад выхода ЭСД атомов Li связан с формированием второго монослоя адсорбированных атомов $\mathrm{Li}$ (схема $c$ на рис. 2), который препятствует выходу атомов Li в вакуум, как это было показано ранее, например, для системы $\mathrm{Na} / \mathrm{NaxAuy} / \mathrm{Au} / \mathrm{W}$ [2].

На рис. 3 приведены зависимости выхода ЭСД атомов $\mathrm{Li}$ от времени напыления атомов $\mathrm{Au}$, т.е. от величины покрытия атомами золота поверхности вольфрама, для трех доз напыления атомов лития: $n_{\mathrm{Li}}: 1.0 \cdot 10^{15}$ atom $/ \mathrm{cm}^{2}, 1.5 \cdot 10^{15}$ atom $/ \mathrm{cm}^{2}$ и $2.0 \cdot 10^{15} \mathrm{atom} / \mathrm{cm}^{2}$, которые можно формально приписать напылению 1.0, 1.5 и 2.0 монослоя $\mathrm{Li}$, соответственно. Сначала проводилось напыление пленки золота на вольфрамовую фольгу, а затем всегда напылялось одно тоже количество атомов лития. Как видно, для времени напыления атомов $\mathrm{Au}$ менее $300 \mathrm{~s}$ с последующим напылением атомов лития в диапазоне $n_{\mathrm{Li}}=(1.0-2.0) \cdot 10^{15}$ atom $/ \mathrm{cm}^{2}$ не приводит к появлению ЭСД атомов Li. За времена меньшие $300 \mathrm{~s}$ напыляется менее одного монослоя атомов золота и эти атомы не принимают участие в формировании $\mathrm{Li}_{x} \mathrm{Au}_{y}$. При напылении атомов лития в концентрации $n_{\mathrm{Li}}=2.0 \cdot 10^{15}$ atom $/ \mathrm{cm}^{2}$ на слой золота, который, в свою очередь, напылялся более $300 \mathrm{~s}$, ЭСД атомов лития наблюдается, т.е. происходит формирование 2D-слоя $\mathrm{Li}_{x} \mathrm{Au}_{y}$ между верхним слоем атомов лития и ближайшим к поверхности вольфрама монослоем золота. При этом формируется 2D-слой $\mathrm{Li}_{x} \mathrm{Au}_{y} \mathrm{c} x<y$. Максимальное значение выхода ЭСД атомов Li наблюдается при времени напыления золота $600 \mathrm{~s}$, что соответствует

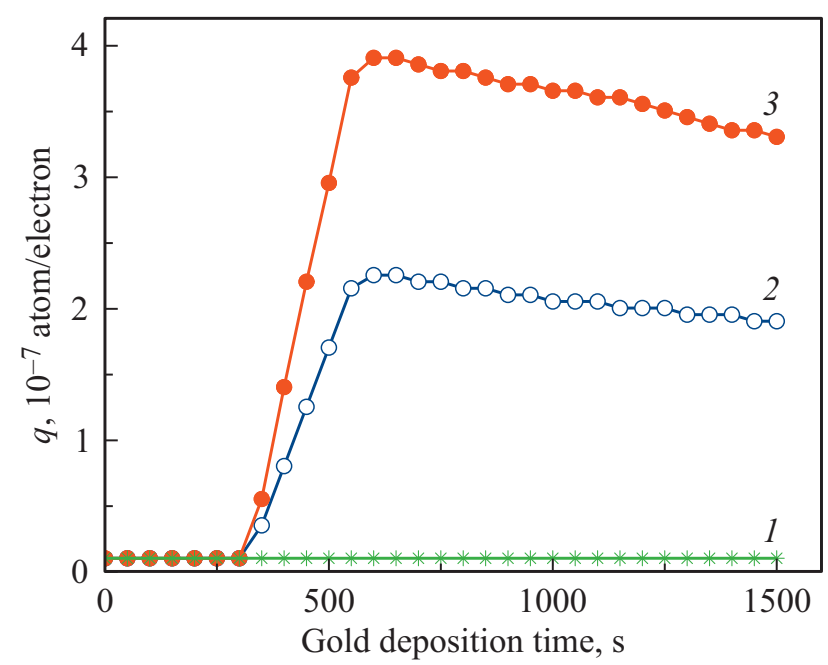

Рис. 3. Выход $q$ атомов $\mathrm{Li}$ при ЭСД с вольфрама, покрытого золотом, при $T=300 \mathrm{~K}$ в зависимости от времени напыления золота для трех концентраций лития $n_{\mathrm{Li}}: 1-1.00 \cdot 10^{15}$ atom $/ \mathrm{cm}^{2}, 2-1.50 \cdot 10^{15}$ atom $/ \mathrm{cm}^{2}$, $3-2.0 \cdot 10^{15} \mathrm{atom} / \mathrm{cm}^{2}$. Энергия бомбардирующих электронов $64 \mathrm{eV}$. 
формированию 2D-слоя LiAu между верхним монослоем атомов лития и ближайшим к поверхности вольфрама монослоем золота (смотри схему на рис. $2, b$ ). Напыление атомов лития на более толстые пленки золота приводит к уменьшению выхода ЭСД атомов Li. Это можно объяснить так: в формировании $\mathrm{Li}_{x} \mathrm{Au}_{y}$ принимает участие только один монослой атомов лития, а $\mathrm{c}$ увеличением числа взаимодействующих с атомами $\mathrm{Li}$ атомов $\mathrm{Au}$ стехиометрия соединения $\mathrm{Li}_{x} \mathrm{Au}_{y}$ изменяется в сторону увеличения $y$ и уменьшения $x$. Можно предположить формирование $\mathrm{LiAu}_{4}$ при времени напыления атомов золота $1600 \mathrm{~s}$. Похожие процессы происходят и при напылении меньшего количества атомов лития $n_{\mathrm{Li}}=1.5 \cdot 10^{15}$ atom $/ \mathrm{cm}^{2}$ на слой золота. Максимальное значение выхода ЭСД атомов Li наблюдается при времени напыления золота $600 \mathrm{~s}$, что соответствует формированию 2D-слоя LiAu между верхним монослоем атомов лития и ближайшим к поверхности вольфрама монослоем золота и можно предположить формирование $2 \mathrm{D}$-слоя $\mathrm{LiAu}_{2}$. Напыление атомов лития на более толстые пленки золота приводит к уменьшению выхода ЭСД атомов Li. Незначительный спад выхода ЭСД атомов $\mathrm{Li}$ всего на $15 \%$, может означать либо медленную диффузию атомов лития вглубь слоя золота, либо слабую зависимость вероятности выхода ЭСД атомов $\mathrm{Li}$ для $\mathrm{Li}_{x} \mathrm{Au}_{y}$, которая зависит от соотношения $x / y$. Полученный нами $2 \mathrm{D}$-слой состоящий из четырех монослоев $\mathrm{Li}_{x} \mathrm{Au}_{y}$ имеет полупроводниковый характер, а полученный в [18] 2D-слой состоящий из пяти монослоев золота, насыщенных атомами лития имеет металлический характер, что может указывать на переход полупроводник-металл при пяти слоях. Это можно объяснить как особенностями формирования слоя $\mathrm{Li}-\mathrm{Au}$ на $\mathrm{Re}$ в [18] и в наших экспериментах, так и тем, что возможно переход полупроводник-металл происходит при напылении атомов Li на золотую пленку толщиной в районе 5 монослоев.

На рис. 4 приведена измеренная при $T=300 \mathrm{~K}$ зависимость $q\left(E_{e}\right)$ выхода ЭСД атомов Li от энергии бомбардирующих электронов $\left(E_{e}\right)$ с поверхности $\mathrm{W}$, покрытого двумя монослоями $\mathrm{Au}$, на поверхность которого был напылен литий $n_{\mathrm{Li}}=2.0 \cdot 10^{15} \mathrm{atom} / \mathrm{cm}^{-2}$ (2 монослоя). В зависимости $q\left(E_{e}\right)$ видно 2 „квазирезонансных“ пика с максимумами при 63.5 и $81.4 \mathrm{eV}$. Эти пики связаны с возбуждением бомбардирующими электронами остовных уровней $\mathrm{Au} 5 p_{3 / 2}$ и $\mathrm{Au} 5 p_{1 / 2}$. Полная ширина на полувысоте составляет 8.8 и $9.4 \mathrm{eV}$ соответственно для остовных уровней $\mathrm{Au} 5 p_{3 / 2}$ и $\mathrm{Au} 5 p_{1 / 2}$. Отношение площадей под пиками составляет 0.72 , что близко к теоретическому спин-орбитальному расщеплению для уровней $\mathrm{Au} 5 p_{3 / 2}$ и $\mathrm{Au} 5 p_{1 / 2}$, которое равно 0.67. Возбуждение остовного уровня Li $1 s$ с энергией связи $E_{b}=54.7 \mathrm{eV}$ не наблюдается. Так, если бы этот уровень возбуждался, то отношение площадей под пиками бы возросло и это отношение зависело бы от количества напыленных атомов лития. Возбуждение остовных уровней $\mathrm{Au} 4 f_{7 / 2}\left(E_{b}=84.0 \mathrm{eV}\right)$ и $\mathrm{Au} 4 f_{5 / 2}\left(E_{b}=87.6 \mathrm{eV}\right)$, если и происходит, то дает незначительный вклад в зависимость $q\left(E_{e}\right)$.

Для объяснения процесса ЭСД атомов Li в системе $\mathrm{Li} / \mathrm{Li}_{x} \mathrm{Au}_{y} / \mathrm{Au} / \mathrm{W}$ воспользуемся идеями, предложенными

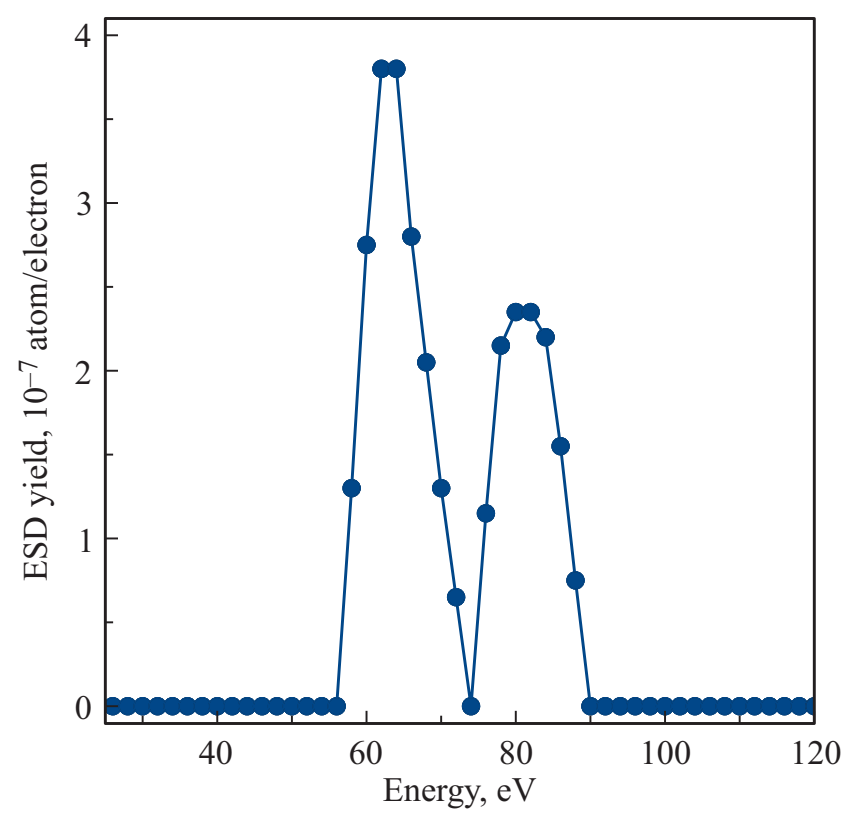

Рис. 4. Выход $q$ атомов $\mathrm{Li}$ при ЭСД с вольфрама, покрытого двумя монослоями золота и двумя монослоями $\mathrm{Li}$, при $T=300 \mathrm{~K}$ в зависимости от энергии бомбардирующих электронов $E_{e}$.

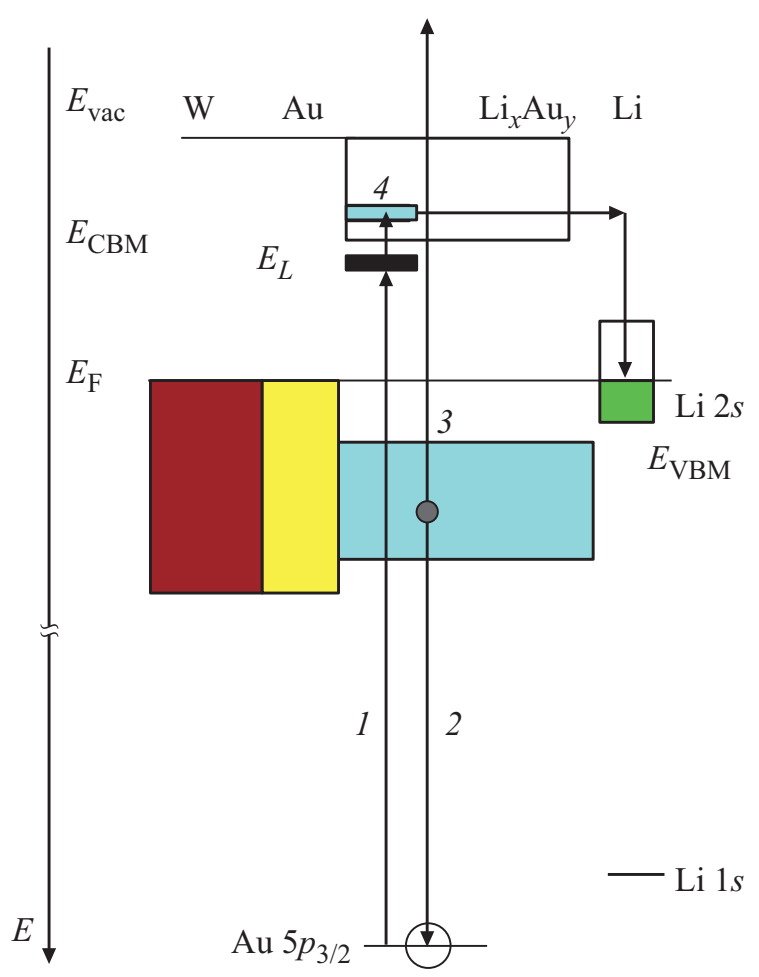

Рис. 5. Схема процессов ЭСД в системе монослой $\mathrm{Li} /$ слой $\mathrm{Li}_{x} \mathrm{Au}_{y}$ /монослой $\mathrm{Au} /$ подложка W. $E_{V в M}$ - энергия, соответствующая максимуму валентной зоны. 
ранее $[1,21]$. Рассмотрим схему процессов на примере возбуждения бомбардирующими электронами уровня $\mathrm{Au}$ $5 p_{3 / 2}$ (рис. 5). Электронное облучение образца приводит к возбуждению электрона с остовного уровня $\mathrm{Au} 5 p_{3 / 2}(1)$ в локальное состояние $E_{L}$ рядом с дном зоны проводимости $E_{C B M}$, опустившееся из зоны проводимости, в поле образовавшейся остовной дырки Аu $5 p^{+}$ в запрещенную зону полупроводника $\mathrm{Li}_{x} \mathrm{Au}_{y}$. Образовавшаяся дырка $\mathrm{Au} 5 p^{+}$нейтрализуется электроном из валентной зоны (2) в слое $\mathrm{Li}_{x} \mathrm{Au}_{y}$. При этом за счет Ожепроцесса происходит выброс электрона (3) в вакуум. Электрон в локальном состоянии $E_{L}$ расположен вблизи дна зоны проводимости $E_{C B M}$ (для системы $\mathrm{Cs} / \mathrm{CsAu}$ он расположен ниже на $50 \mathrm{meV}$ [21]) и он может быть легко захвачен в зону проводимости (4). Электрон из зоны проводимости захватывается (5) на незанятые состояния атома $\mathrm{Li}$ в монослое атомов лития с образованием нейтрального атома $\mathrm{Li}^{0}$ в монослое $\mathrm{Li}$. Образование нейтрального атома $\mathrm{Li}$ приводит к увеличению его размера по сравнению с атомом $\mathrm{Li}$ в монослое $\mathrm{Li}$, и он выталкивается с поверхности. Следует отметить, что процесс ЭСД атомов $\mathrm{Li}$ связан с электронными переходами в области интерфейса: монослой атомов $\mathrm{Li}$ и ближайший к нему слой $\mathrm{Li}_{x} \mathrm{Au}_{y} . \mathrm{B}$ нейтрализации дырки $\mathrm{Au} 5 p^{+}$может принять участие также электрон с остовного уровня Li $1 s$, но это процесс на наш взгляд менее вероятен, так как необходимо дополнительно нейтрализовать дырку Li $1 s^{+}$. Точно такие же процессы происходят при электронном возбуждении остовного уровня $\mathrm{Au} 5 p_{1 / 2}$.

\section{4. Заключение}

Обнаружена и исследована электронно-стимулированная десорбция атомов $\mathrm{Li}$ в системе $\mathrm{Li} / \mathrm{Li}_{x} \mathrm{Au}_{y} / \mathrm{Au} / \mathrm{W}$. Показано, что при адсорбции атомов лития на золоте формируется полупроводниковый 2D-слой LixAuy в промежутке между монослоем лития и монослоем золота, ближайшем к поверхности вольфрама. При напылении двух монослоев золота и лития формируется LiAu. Для более толстых пленок золота в случае напыления на него 2 монослоев лития также формируется 2D-слои с различной стехиометрией $\mathrm{Li}_{x} \mathrm{Au}_{y}$ с дефицитом атомов лития. Наблюдается „квазирезонансная“ зависимость выхода ЭСД атомов Li от энергии возбуждающих электронов, связанная с возбуждением остовных уровней $\mathrm{Au} 5 p_{3 / 2}$ и $\mathrm{Au} 5 p_{1 / 2}$. Предложена модель процессов, происходящих в системе $\mathrm{Li} / \mathrm{Li}_{x} \mathrm{Au}_{y} / \mathrm{Au} / \mathrm{W}$. Процесс ЭСД захватывает атомы, расположенные в адсорбированном слое атомов $\mathrm{Li}$ и ближайшем к нему слое $\mathrm{Li}_{x} \mathrm{Au}_{y}$.

\section{Финансирование работы}

Исследование выполнено при финансовой поддержке РФФИ в рамках научного проекта № 20-02-00370.

\section{Конфликт интересов}

Авторы заявляют, что у них нет конфликта интересов.

\section{Список литературы}

[1] Ю.А. Кузнецов, М.Н. Лапушкин. ФТТ 62, 1949 (2020).

[2] В.Н. Агеев, Ю.А. Кузнецов, Н.Д. Потехина. ФТТ 55, 2447 (2013).

[3] В.Н. Агеев, Ю.А. Кузнецов. ФТТ 50, 365 (2008).

[4] M.V. Knat'ko, M.L. Lapushkin, V.I. Paleev. Phys. Low-Dime. Struct. 9-10, 85 (1999).

[5] W.E. Spicer, A.N. Sommer, J.G. White. Phys. Rev. 115, 57 (1959).

[6] M. Jansen. Chem. Soc. Rev. 37, 1826 (2008).

[7] G.K. Wertheim, C.W. Bates, D.N.E. Buchanan. Solid Status Commun. 30, 473 (1979).

[8] M. Skottke-Klein, A. Bottcher, R. Imbeck, S. Kennou, A. Morgante, G. Ertl. Thin Solid Films 203, 131 (1991).

[9] М.В. Кнатько, М.Н. Лапушкин, В.И. Палеев. Письма в ЖТФ 24, 48 (1998).

[10] N.E. Christensen, J. Kollar. Solid Status Commun. 46, 72 (1983).

[11] G.H. Grosch, K.-J. Range. J. Alloys Compounds 233, 30 (1996).

[12] R. Sarmiento-Perez, T.F.T. Cerqueira, I. Valencia-Jaime, M. Amsler, S. Goedecker, S. Botti, M.A.L. Marques, A.H. Romero. New J. Phys. 15, 115007 (2013).

[13] G.H. Grosch, K.-J. Range. J. Alloys Compounds 233, 39 (1996).

[14] М.В. Кнатько, М.Н. Лапушкин, В.И. Палеев. ЖТФ. 68, 108 (1998).

[15] J.A. Rodriguez, J. Hrbek, Y.-W. Yang M. Kuhn, T.K. Sham. Surf. Sci. 293, 260 (1993).

[16] Z. Zeng, W.-I. Liang, Y.-H. Chu, H. Zheng. Faraday Discuss 176, 95 (2014).

[17] R.A. Alvarez-Bayona, M. Cortez-Valadez, F. MartínezSuárezc, J.J. Cruz-Riverad, M. Flores-Acosta. Phys. E 108, 169 (2019).

[18] В.Н. Агеев, Е.Ю. Афанасьева. ФТТ 48, 2217 (2006).

[19] U.Kh. Rasulev, E.Ya. Zandberg. Prog. Surf. Sci. 28, 181 (1988).

[20] G. Kienast, J. Verma, W. Klemm, Z. Anorg. Allgem. Chem. 310, 143 (1961).

[21] Ю.А. Кузнецов, М.Н. Лапушкин, Физико-химические аспекты изучения кластеров, наноструктур и наноматериалов 7, 333 (2015).

Редактор К.В. Емцев 